\title{
Preparation and magnetic properties of nano size nickel ferrite particles using hydrothermal method
}

\author{
Kamellia Nejati* and Rezvanh Zabihi
}

\begin{abstract}
Background: Nickel ferrite, a kind of soft magnetic materials is one of the most attracting class of materials due to its interesting and important properties and has many technical applications, such as in catalysis, sensors and so on. In this paper the synthesis of $\mathrm{NiFe}_{2} \mathrm{O}_{4}$ nanoparticles by the hydrothermal method is reported and the inhibition of surfactant (Glycerol or Sodium dodecyl sulfate) on the particles growth is investigated.

Methods: For investigation of the inhibition effect of surfactant on $\mathrm{NiFe}_{2} \mathrm{O}_{4}$ particles growth, the samples were prepared in presence of Glycerol and Sodium dodecyl sulfate. The X-ray powder diffraction (XRD), transmission electron microscopy (TEM), Fourier transform infrared spectroscopy (FT-IR), vibrating sample magnetometer (VSM) and inductively coupled plasma atomic emission spectrometer (ICP-AES) techniques were used to characterize the samples.
\end{abstract}

Results: The results of XRD and ICP-AES show that the products were pure $\mathrm{NiFe}_{2} \mathrm{O}_{4}$ and also nanoparticles grow with increasing the temperature, while surfactant prevents the particle growth under the same condition. The average particle size was determined from the Scherrer's equation and TEM micrographs and found to be in the range of 50-60 nm that decreased up to 10-15 nm in presence of surfactant. The FT-IR results show two absorption bands near to 603 and $490 \mathrm{~cm}^{-1}$ for the tetrahedral and octahedral sites respectively. Furthermore, the saturated magnetization and coercivity of $\mathrm{NiFe}_{2} \mathrm{O}_{4}$ nanoparticles were in the range of $39.60 \mathrm{emu} / \mathrm{g}$ and $15.67 \mathrm{Q}_{\mathrm{e}}$ that decreased for samples prepared in presence of surfactant. As well as, the nanoparticles exhibited a superparamagnetic behavior at room temperature.

Conclusions: Nanosized nickel ferrite particles were synthesized with and without surfactant assisted hydrothermal methods. The results show that with increasing of temperature, the crystallinity of nanoparticles is increased. In the presence of surfactants, the crystallinity of $\mathrm{NiFe}_{2} \mathrm{O}_{4}$ nanoparticles decreased in comparison with surfactant- free prepared samples. All of the nickel ferrite nanoparticles were superparamagnetic at room temperature.

\section{Graphical abstract}

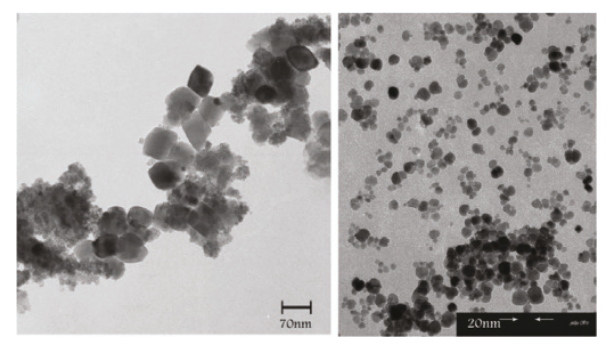

* Correspondence: k_nejati@pnu.ac.ir

Department of Chemistry, Payame Noor University, PO Box 19395-3697, Tehran, Iran 


\section{Introduction}

Nanosized spinel ferrite particles, a kind of soft magnetic materials with structural formula of $\mathrm{MFe}_{2} \mathrm{O}_{4}(\mathrm{M}=$ divalent metal ion, e.g. $\mathrm{Mn}, \mathrm{Mg}, \mathrm{Zn}, \mathrm{Ni}, \mathrm{Co}, \mathrm{Cu}$, etc.), are one of the most attracting class of materials due to their interesting and important properties such as low melting point, high specific heating, large expansion coefficient, low saturation magnetic moment and low magnetic transition temperature, etc.[1,2]. Because of these properties, the spinel ferrites have many technical applications, such as in photoelectric devices [3] catalysis [4], sensors [5], nano devices [6], microwave devices $[7,8]$ and magnetic pigments [9].

Remarkable electrical and magnetic properties of ferrites depend upon the nature of the ions, their charges and their distribution among tetrahedral (A) and octahedral (B) sites [10]. Nickel ferrite is one of the versatile and technologically important soft ferrite materials because of its typical ferromagnetic properties, low conductivity and thus lower eddy current losses, high electrochemical stability, catalytic behavior, abundance in nature, etc[8]. This ferrite is an inverse spinel in which eight units of $\mathrm{NiFe}_{2} \mathrm{O}_{4}$ go into a unit cell of the spinel structure. Half of the ferric ions preferentially fill the tetrahedral sites (A-sites) and the others occupy the octahedral sites (B-sites) [11]. Thus the compound can be represented by the formula $\left(\mathrm{Fe}^{3+}\right)_{\mathrm{A}}\left[\mathrm{Ni}^{2+} \mathrm{Fe}^{3+}\right]_{\mathrm{B}} \mathrm{O}_{4}{ }^{2-}$ [12]. The synthesis of spinel ferrite nanoparticles has been intensively studied in the recent years and the principal role of the preparation conditions on the morphological and structural features of the ferrites is discussed [13-16]. Large-scale applications of ferrites with small particles and tailoring of specific properties have prompted the development of widely used chemical methods, including hydrothermal [10], sonochemical reactions [17], sol-gel methods[18], microwave plasma [19], co-precipitation [20], microemulsion methods [21], citrate precursor techniques [22] and mechanical alloying [23] for the fabrication of stoichiometric and chemically pure spinel ferrite nanoparticles. The hydrothermal route is one of the most commonly used techniques owing to its economics and high degree of compositional control. In addition, the hydrothermal synthesis does not require extremely high-processing temperature or sophisticated processing. For example, ferrites can be prepared via the hydrothermal route at a temperature of $\sim 150^{\circ} \mathrm{C}$, whereas the solid state method requires a temperature of $800^{\circ} \mathrm{C}$ [10].

In this work, nano crystalline nickel ferrite, $\mathrm{NiFe}_{2} \mathrm{O}_{4}$, was successfully prepared via reaction between metal chlorides in ethylacetate solution with and without surfactant assisted processes. Investigations on the particle size, morphology and magnetic properties of inverse spinel nickel ferrite in at different conditions are carried out by the XRD, FT-IR, TEM, ICP-AES and VSM techniques.

\section{Results and discussion FT-IR analysis}

Figure 1(a-c) shows the FT- IR absorption spectra of nanocrystalline $\mathrm{NiFe}_{2} \mathrm{O}_{4}$ samples prepared without and with surfactant-assisted methods (Glyserole and Sodium dodecyl sulfate) which were recorded in the range of 400-4000 $\mathrm{cm}^{-1}$. On the bases of literature data, in the range of $1000-100 \mathrm{~cm}^{-1}$, the FT-IR bands of solids are usually assigned to vibration of ions in the crystal lattice $[10,24]$. In all spinels and particularly in ferrites, two main broad metal oxygen bands are seen in the FT-IR spectra. Therefore the highest one, observed at $v_{1}=603$ $\mathrm{cm}^{-1}$ (Figure 1a), corresponds to intrinsic stretching vibrations of the metal at the tetrahedral site, $\left(\mathrm{M}_{\text {tetra }}-\mathrm{O}\right)$, whereas the lowest band, that observed at $v_{2}=490 \mathrm{~cm}^{-1}$ is assigned to octahedral metal stretching vibration $\left(\mathrm{M}_{\mathrm{octa}}-\mathrm{O}\right)$ [24]. Figure $1(\mathrm{~b}-\mathrm{c})$, shows a difference in the positions and area of $v_{1}$ and $v_{2}$ absorptions bands, that may be due to the changed conditions of formation of samples by surfactant assisted process. Because, the positions and intensities of the bands depends strongly on the methods and conditions of preparation [12,25].

\section{Structural analysis}

The X-ray diffraction patterns of the prepared samples are shown in Figure 2(a-g).

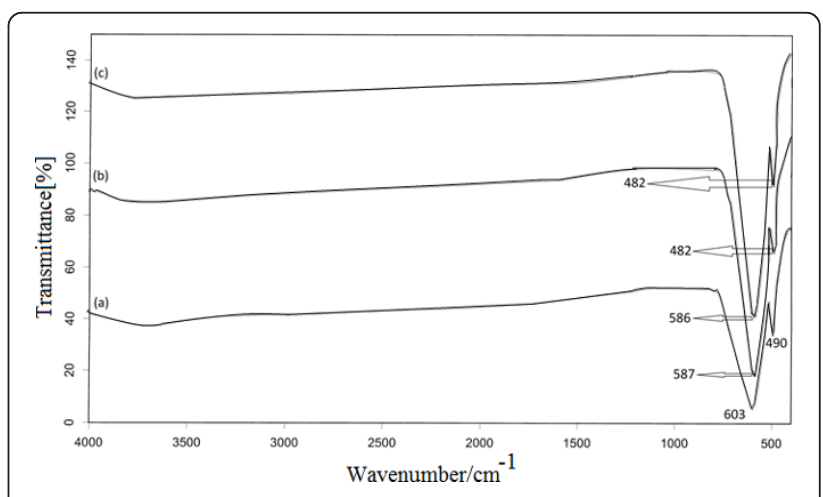

Figure 1 FT- IR spectra of $\mathrm{NiFe}_{2} \mathrm{O}_{4}$ nanoparticles prepared (a) without surfactant,(b) Glycerol-assisted and (c) Sodium dodecyle sulfate assisted methods. 
The samples (a) and (b) that prepared without surfactant at 45 and $80^{\circ} \mathrm{C}$, consisted of amorphous solids which have not been detected by XRD technique. This may be related to the formation of amorphous state of nickel, iron oxides and or $\mathrm{NiFe}_{2} \mathrm{O}_{4}$ nanoparticles. Weak diffraction peaks in the samples (c) and (d), prepared without surfactant at 100 and $130^{\circ} \mathrm{C}$, were attributed to the effect of increasing of temperature on the improvement of crystalline properties of amorphous nickel ferrite and also the conversion of some $\mathrm{Ni}$ and Fe oxides to produce nickel ferrite crystallites. Increasing of temperature up to $150^{\circ} \mathrm{C}$ led to the formation of well crystalline nickel ferrite (sample e). As Figure 2 shows, in the presence of surfactants (glycerol and sodium dodecyl sulfate) at $150^{\circ} \mathrm{C}$ in samples (f) and (g), crystallinity of $\mathrm{NiFe}_{2} \mathrm{O}_{4}$ nanoparticles was decreased in comparison with surfactant- free prepared samples [26].

In the case of sample (g), prepared by sodium dodecyl solfate assisted method, some impurities were observed. The XRD patterns of samples (c-g) exhibited the reflection plans (220), (311), (222), (400), (422), (511) and (440) that indicate the spinel cubic structure [10,27-30]. The XRD patterns of the standard $\mathrm{NiFe}_{2} \mathrm{O}_{4}$ from JCPDS No. 10-325 has been presented in Figure 2. The average crystallite size was calculated from the most intense peak (311) using the Scherrer's formula:

$$
\mathrm{D}=\mathrm{k} \lambda / \beta \cos \theta,
$$

where, $\mathrm{D}$ is the average crystalline size, $\mathrm{k}$ the Scherrer constant (0.89), $\lambda$ the $\mathrm{X}$-ray wavelength used, $\beta$ the angular linewidth of half maximum intensity and $\theta$ is the Bragg's angle in degrees unit. The results are shown in Table 1 .

Table 1 shows that with increase in the temperature from $100^{\circ} \mathrm{C}$ to $150^{\circ} \mathrm{C}$ in samples (c-e), the average size of $\mathrm{NiFe}_{2} \mathrm{O}_{4}$ nanoparticles also increases that can be

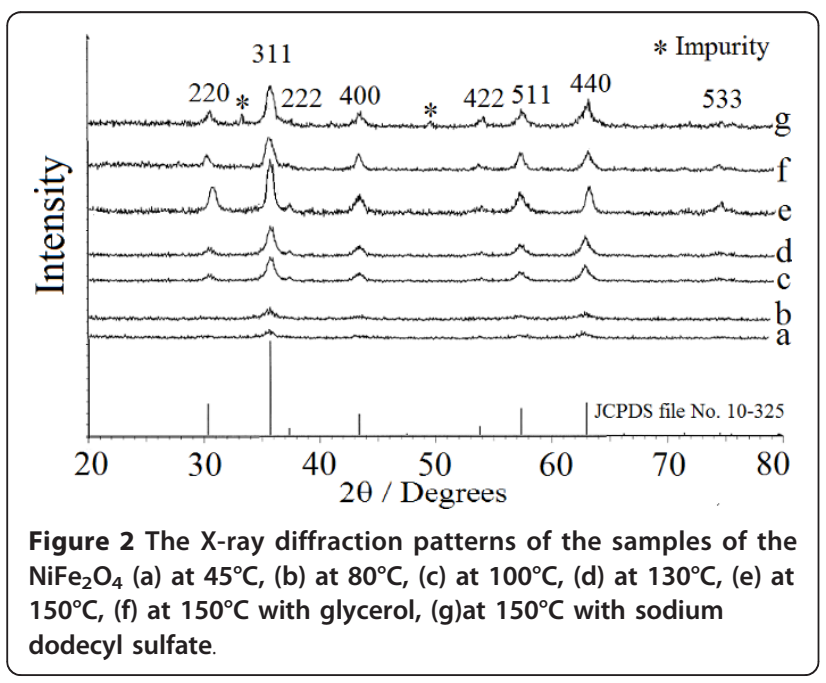

Table 1 The crystallite size (D) of the $\mathrm{NiFe}_{2} \mathrm{O}_{4}$ present in the samples $(\mathbf{c}-\mathrm{g})$

\begin{tabular}{lll}
\hline sample & temperature $\left({ }^{\circ} \mathbf{C}\right)$ & $\mathbf{D}(\mathbf{n m})$ \\
\hline $\mathrm{c}$ & 100 & 30 \\
\hline $\mathrm{d}$ & 130 & 39 \\
\hline $\mathrm{e}$ & 150 & 53 \\
\hline $\mathrm{f}$ & 150 & 13 \\
\hline $\mathrm{g}$ & 150 & 12 \\
\hline
\end{tabular}

attributed to the temperature assists crystal growth and/ or the redistribution of cations among octahedral and tetrahedral sites [12]. Additionally, Figure 2 shows that in the presence of surfactant about samples ( $\mathrm{f}$ and $\mathrm{g}$ ), diffraction peak (311) is broad and therefore smaller $\mathrm{NiFe}_{2} \mathrm{O}_{4}$ nanoparticles are formed. This fact may be due to the role of surfactants in the decrease of the agglomeration of particles [31]. From the ICP-AES result, the atomic ratio of $\mathrm{Ni}-\mathrm{Fe}$ is 0.49 , which is close to that of $\mathrm{NiFe}_{2} \mathrm{O}_{4}$.

\section{Morphology and microstructure}

In order to investigate the morphology and particle size of products, the TEM images of samples (e-g), were obtained and are shown in Figure 3(a-c). From the TEM micrographs, it is clear that the nanoparticles obtained without surfactant are cubic-like but are not uniform (Figure 3a). On the other hand, in the presence of surfactant, the samples are sphere-like and uniform in both morphology and particle size (Figure $3 \mathrm{~b}$ and 3c). Average grain-size obtained from TEM image of sample (e) is approximately $60 \mathrm{~nm}$, which is in good agreement with the size determination by Scherrer equation from XRD patterns. In the cases of samples (f) and (g), the average size obtained were about $10-15 \mathrm{~nm}$.

\section{Magnetic properties}

Figure 4(a and $4 \mathrm{~b})$ shows the hysteresis loops obtained from VSM measurements for surfactant- assisted prepared $\mathrm{NiFe}_{2} \mathrm{O}_{4}$ nano particles (samples $\mathrm{f}$ and $\mathrm{g}$ ) at room temperature. The magnetic properties of the $\mathrm{NiFe}_{2} \mathrm{O}_{4}$ with an inverse spinel structure can be explained in terms of the cations distribution and magnetization originates from $\mathrm{Fe}^{3+}$ ions at both tetrahedral and octahedral sites and $\mathrm{Ni}^{2+}$ ions in octahedral sites [32,33]. Hysteresis loops in Figure 4(a and 4b) are typical for soft magnetic materials and the "S" shape of the curves together with the negligible coercivity $\left(\mathrm{H}_{\mathrm{c}}=0.60\right.$ and $0.64 \mathrm{Q}_{\mathrm{e}}$ ) indicate the presence of small magnetic particles exhibiting superparamagnetic behaviors [34]. In superparamagnetic materials, responsiveness to an applied magnetic field without retaining any magnetism after removal of the magnetic field is observed. This behavior is an important property for magnetic targeting carriers 


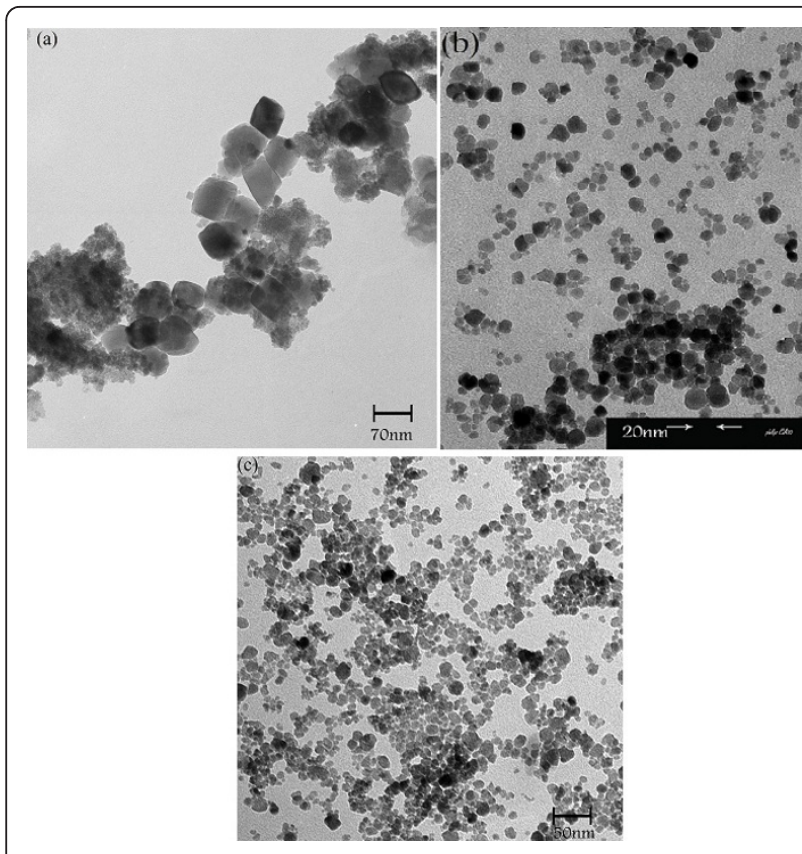

Figure 3 The TEM images of (a) sample e, (b) sample $f$, (c) sample $\mathbf{g}$.

[35]. In fact, the difference between ferromagnetism and superparamagnetism fabricates in the particle size. Literature data imply that when the diameter of particles is less than $30 \mathrm{~nm}$, the particles show the character of superparamagnetism $[34,36]$. Figure 5 shows the magnetic hysteresis loop for $\mathrm{NiFe}_{2} \mathrm{O}_{4}$ sample (e), prepared without surfactant. The curve is "S" shape with low coercivity $\left(15.67 \mathrm{O}_{\mathrm{e}}\right)$. This sample showed superparamagnetic behavior. The saturation magnetization $\left(M_{s}\right)$ and the coercivity $\left(\mathrm{H}_{\mathrm{c}}\right)$ values of products, are listed in Table 2.

It is obvious from Table 2 that: (a) the values of saturation magnetization for $\mathrm{NiFe}_{2} \mathrm{O}_{4}$ nanoparticles are significantly lower than the multidomain bulk particles (55 emu/g). Smit and Wijn have reported $\mathrm{M}_{\mathrm{s}}$ equal to $50 \mathrm{emu} / \mathrm{g}$ for bulk nickel ferrite particles [37]. Nathani and Misra have measured $M_{s}$ equal to $25 \mathrm{emu} / \mathrm{g}$ for $\mathrm{NiFe}_{2} \mathrm{O}_{4}$ nanoparticles with size $8 \mathrm{~nm}$ [38]. (b) The amounts of $\mathrm{M}_{\mathrm{s}}$ and $\mathrm{H}_{\mathrm{c}}$ for samples (g and $\mathrm{f}$ ) are equal to $34.45-35.10 \mathrm{emu} / \mathrm{g}$ and $0.60-0.64 \mathrm{O}_{\mathrm{e}}$ respectively, which increase to $39.60 \mathrm{emu} / \mathrm{g}$ and $15.67 \mathrm{Q}_{\mathrm{e}}$ for sample (e). In fact, the magnetic behavior of nickel ferrite nanoparticles is very sensitive to the crystallinity and particle size. The increase in saturation magnetization was most likely attributed to the increasing of crystallinity and particle size of the samples [39] and can be explained on the basis of changes in exchange interactions between tetrahedral and octahedral sub-lattices[40]. In case of nickel ferrite, any configuration of $\mathrm{Ni}^{2+}$ and $\mathrm{Fe}^{3+}$ ions in both octahedral and tetrahedral sites, tends to
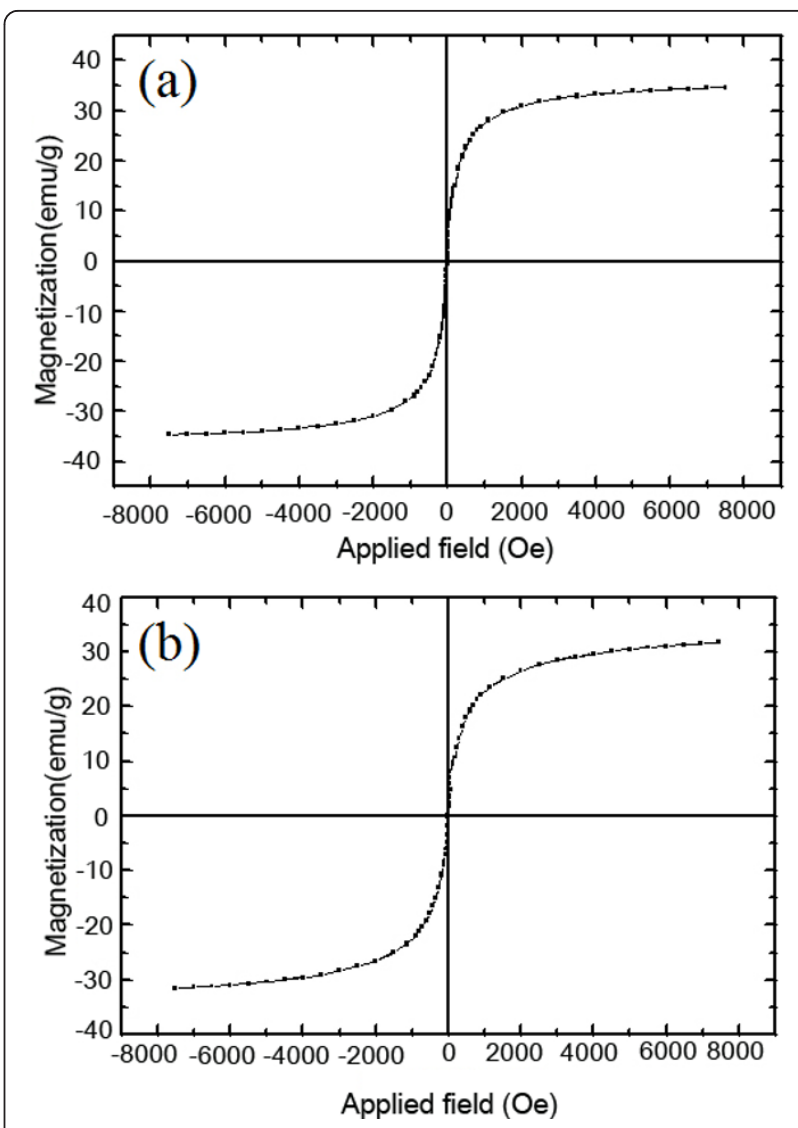

Figure 4 Hysteresis loop of (a) sample $f$, (b) sample $\mathbf{g}$.

increase the net magnetization per formula unit [12]. On the other hand, variation of coercivity with particle size can be explained on the basis of domain structure, critical diameter, strains, magneto crystalline anisotropy and shape anisotropy of crystal [39]. Therefore the magnetic behavior of nano-size nickel ferrites can be a collective effect of these interactions [41].

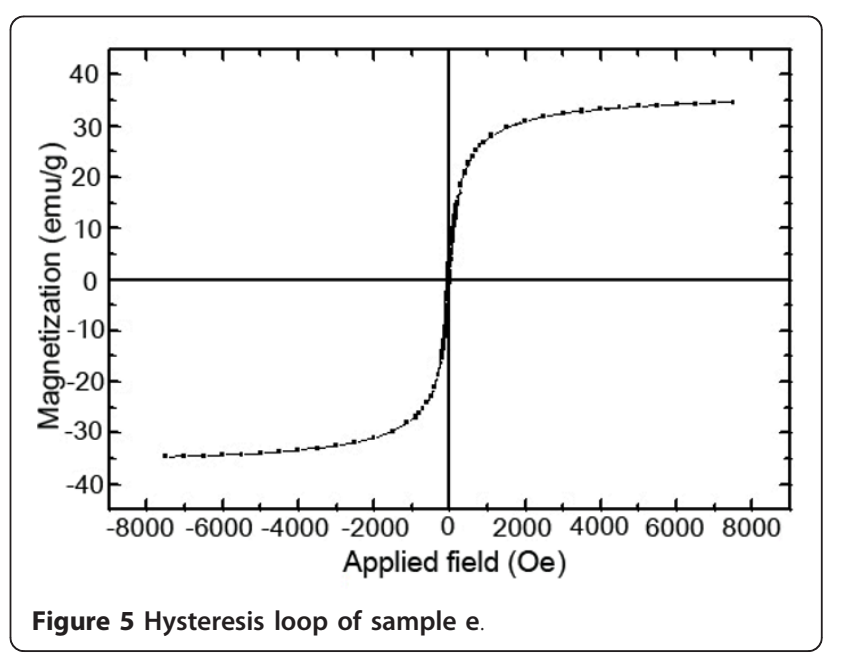


Table 2 The observed values of saturation magnetization and the coercivity of $\mathrm{NiFe}_{2} \mathrm{O}_{4}$ nanoparticles

\begin{tabular}{llll}
\hline sample & particle size $(\mathbf{n m})$ & $\mathbf{M}_{\mathbf{s}}(\mathbf{e m u} / \mathbf{g})$ & $\mathbf{H}_{\mathbf{c}}\left(\mathbf{O}_{\mathbf{e}}\right)$ \\
\hline $\mathrm{f}$ & 13 & 35.10 & 0.64 \\
\hline $\mathrm{g}$ & 12 & 34.45 & 0.60 \\
\hline $\mathrm{e}$ & 53 & 39.60 & 15.67 \\
\hline
\end{tabular}

\section{Conclusions}

Nanosized nickel ferrite particles were synthesized with and without surfactant assisted hydrothermal methods. The FT-IR spectra showed two characteristic metal oxygen vibrational bands. The average particle size of samples was in the range of $12-53 \mathrm{~nm}$, as revealed by XRD and TEM techniques. The temperature rise up to $150^{\circ} \mathrm{C}$ led to the increasing of crystallinity of nanoparticles. In the presence of surfactants, the crystallinity of $\mathrm{NiFe}_{2} \mathrm{O}_{4}$ nanoparticles decreased in comparison with surfactantfree prepared samples. All of the nickel ferrite nanoparticles were superparamagnetic at room temperature. The saturation magnetization and coercivity values were found to be low, which attributed to the various parameters such as crystallinity and particle size. The saturation magnetization and coercivity were reduced with decreasing of crystallinity and particle size of nanoparticles.

\section{Experimental \\ Materials}

$\mathrm{NiCl}_{2} \cdot 6 \mathrm{H}_{2} \mathrm{O}, \mathrm{FeCl}_{3} \cdot 6 \mathrm{H}_{2} \mathrm{O}, \mathrm{NaOH}$, Triethyl amine, Ethyl acetate, Glycerol and Sodium dodecyl sulfate were purchased from Merck chemical company and were used as received without further purification. The deionized water used in all experiments, had a conductivity of less than $10^{-6} \mathrm{Scm}^{-1}$.

\section{Synthesis}

A $0.4 \mathrm{M}(25 \mathrm{~mL})$ solution of iron chloride $\left(\mathrm{FeCl}_{3} \cdot 6 \mathrm{H}_{2} \mathrm{O}\right)$ and a $0.2 \mathrm{M}(25 \mathrm{~mL})$ solution of nickel chloride $\left(\mathrm{NiCl}_{2} \cdot 6 \mathrm{H}_{2} \mathrm{O}\right)$ in double distilled deionized water were mixed with vigorous stirring. $5 \mathrm{M}$ triethyl amine in ethylacetate solution was used to adjust the $\mathrm{pH}$ at 10 . The mixture was heated at different temperatures $(45,80$, 100,130 and $150^{\circ} \mathrm{C}$ ) for $18 \mathrm{~h}$. Hydrothermal synthesis at 100,130 and $150^{\circ} \mathrm{C}$, were carried out in a Teflon-lined autoclave reactor. The black precipitate was filtered off, washed with deionized water and dried in a vacuum oven at $70^{\circ} \mathrm{C}$ for $3 \mathrm{~h}$. Also we prepared $\mathrm{NiFe}_{2} \mathrm{O}_{4}$ nanoparticles via surfactant assisted process. $0.078 \mathrm{M}$ of surfactant (Glycerol or Sodium dodecyl sulfate) was dissolved in $35 \mathrm{~mL}$ deionized water and was added to the solution of salts under vigorous stirring. Adjustment of $\mathrm{pH}$ and other processes were performed as above at $150^{\circ} \mathrm{C}$.

\section{Measurements}

Infrared spectra were recorded in the range of 400-4000 $\mathrm{cm}^{-1}$ with a Bruker vector 22 FT-IR spectrometer from samples in $\mathrm{KBr}$ pellets. The structural characterization was performed using Brucker AXS (model D8 Advance) $\mathrm{X}$-ray powder diffractometer $\left(\mathrm{Cu} \mathrm{K} \mathrm{K}_{\alpha}\right.$ radiation source, $\lambda$ $=0.154 \mathrm{~nm}$ ) with the Bragg angle ranging from $10-70^{\circ}$ generated at $40 \mathrm{kV}$ and $35 \mathrm{~mA}$ at room temperature. Transmission electron microscopy (TEM) analysis was performed using Cambridge, stereo scan 360, 1990, 100 $\mathrm{kV}$ accelerating voltage. The magnetic measurements were carried out at room temperature by using a vibrating sample magnetometer, model VSM, BHV-55, Riken Japan with a magnetic field up to $8 \mathrm{kQ}$. Inductively coupled plasma atomic emission spectrometer (ICPAES) was carried out on a Thermo Fisher Scientific ICP-IRIS Advantage.

\section{Acknowledgements}

The author thanks the Payame Noor University, Tabriz center for the financial support of project.

\section{Authors' contributions}

KN made a significant contribution to Survey results and data and their analysis and revising the manuscript for intellectual content. RZ participated in the synthesis of samples and collection of data and experimental work and analysis. All authors read and approved the final manuscript.

\section{Competing interests}

The authors declare that they have no competing interests.

Received: 17 December 2011 Accepted: 30 March 2012 Published: 30 March 2012

\section{References}

1. Xu Q, Wei Y, Liu Y, Ji X, Yang L, Gu M: Preparation of Mg/Fe spinel ferrite nanoparticles from $\mathrm{Mg} / \mathrm{Fe}-\mathrm{LDH}$ microcrystallites under mild conditions. Solid State Sci 2009, 11(2):472-478

2. Tian MB: Magnetic Material Beijing: Tsinghua University Press; 2001.

3. Hu J, Li L-S, Yang W, Manna L, Wang L-W, Alivisatos AP: Linearly Polarized Emission from Colloidal Semiconductor Quantum Rods. Science 2001, 292(5524):2060-2063.

4. Sloczynski J, Janas J, Machej T, Rynkowski J, Stoch J: Catalytic activity of chromium spinels in SCR of NO with NH3. Appl Catal B 2000, 24(1):45-60.

5. Pena MA, Fierro JLG: Chemical Structures and Performance of Perovskite Oxides. Chem Rev 2001, 101(7):1981-2018.

6. Ajayan PM, Redlich P, Ru"hle M: Structure of carbon nanotube-based nanocomposites. J Micro 1997, 185(2):275-282.

7. Baykal A, Kasapoglun, Durmus Z, Kavas H, Toprak MS, Koseoglu Y: CTABAssisted Hydrothermal Synthesis and Magnetic Characterization of $\mathrm{Ni}_{\mathrm{X}} \mathrm{Co}_{1-x} \mathrm{Fe}_{2} \mathrm{O}_{4}$ Nanoparticles $(\mathrm{x}=0.0,0.6,1.0)$. Turk J Chem 2009, 33:33-45.

8. Gunjakar JL, More AM, Gurav KV, Lokhande CD: Chemical synthesis of spinel nickel ferrite (NiFe2O4) nano-sheets. Appl Surf Sci 2008, 254(18):5844-5848

9. Wang $X$, Yang G, Zhang Z, Yan L, Meng J: Synthesis of strong-magnetic nanosized black pigment $\mathrm{Zn}_{\mathrm{x}} \mathrm{Fe}_{3-\mathrm{x}} \mathrm{O}_{4}$. Dyes Pigm 2007, 74(2):269-272.

10. Baykal Al, Kasapoglu N, Koseoglu Yk, Toprak MS, Bayrakdar H: CTAB-assisted hydrothermal synthesis of NiFe2O4 and its magnetic characterization. J Alloys Compd 2008, 464(1-2):514-518.

11. Goldman A: Modern Ferrite Technology. New York: Marcel Dekker; 1993.

12. Alarifi A, Deraz NM, Shaban S: Structural, morphological and magnetic properties of $\mathrm{NiFe}_{2} \mathrm{O}_{4}$ nano-particles. J Alloys Compd 2009, 486(12):501-506. 
13. Manova E, Tsoncheva T, Paneva D, Mitov I, Tenchev K, Petrov L: Mechanochemically synthesized nano-dimensional iron-cobalt spinel oxides as catalysts for methanol decomposition. Appl Catal A 2004, 277(1-2):119-127.

14. Ferreira TAS, Waerenborgh JC, Mendonsa MHRM, Nunes MR, Costa FM: Structural and morphological characterization of $\mathrm{FeCO}_{2} \mathrm{O}_{4}$ and $\mathrm{CoFe}_{2} \mathrm{O}_{4}$ spinels prepared by a coprecipitation method. Solid State Sci 2003, 5(2):383-392.

15. De Guire M: The cooling rate dependence of cation distributions in $\mathrm{CoFe}_{2} \mathrm{O}_{4}$. J Appl Phys 1989, 65(8):3167-3172.

16. Li S: Cobalt-ferrite nanoparticles: Structure, cation distributions, and magnetic properties. J Appl Phys 2000, 87(9):6223-6225.

17. Shafi KVPM, Gedanken A, Prozorov R, Balogh J: Sonochemical Preparation and Size-Dependent Properties of Nanostructured CoFe2O4 Particles. Chem Mater 1998, 10(11):3445-3450.

18. Kim C: Growth of ultrafine Co-Mn ferrite and magnetic properties by a sol-gel method. J Appl Phys 1999, 85(8):5223-5225.

19. Hochepied JF, Bonville P, Pileni MP: Nonstoichiometric Zinc Ferrite Nanocrystals: Syntheses and Unusual Magnetic Properties.J Phys Chem 2000, B 104(5):905-912.

20. Kim Yl, Kim D, Lee CS: Synthesis and characterization of CoFe2O4 magnetic nanoparticles prepared by temperature-controlled coprecipitation method. Phys B(Amestherdam, Neth) 2003, 337(1-4):42-51.

21. Feltin N, Pileni MP: New Technique for Synthesizing Iron Ferrite Magnetic Nanosized Particles. Langmuir 1997, 13(15):3927-3933.

22. Prasad S, Gajbhiye NS: Magnetic studies of nanosized nickel ferrite particles synthesized by the citrate precursor technique. J Alloys Compd 1998, 265(1-2):87-92.

23. Shi $Y$, Ding J, Liu $X$, Wang J: $\mathrm{NiFe}_{2} \mathrm{O}_{4}$ ultrafine particles prepared by coprecipitation/mechanical alloying. J Magn Magn Mater 1999, 205(23):249-254.

24. Salavati-Niasari M, Davar F, Mahmoudi T: A simple route to synthesize nanocrystalline nickel ferrite (NiFe2O4) in the presence of octanoic acid as a surfactant. Polyhedron 2009, 28(8):1455-1458.

25. Deraz NM: Production and characterization of pure and doped copper ferrite nanoparticles. J Anal Appl Pyrolysis 2008, 82(2):212-222.

26. Maaz K, Karim S, Mumtaz A, Hasanain SK, Liu J, Duan JL: Synthesis and magnetic characterization of nickel ferrite nanoparticles prepared by coprecipitation route. J Magn Magn Mater 2009, 321(12):1838-1842.

27. El-Sayed AM: Influence of zinc content on some properties of $\mathrm{Ni}-\mathrm{Zn}$ ferrites. Ceram Int 2002, 28(4):363-367.

28. Fu Y-P, Pan K-Y, Lin C-H: Microwave-induced combustion synthesis of $\mathrm{Ni}_{0.25} \mathrm{Cu}_{0.25} \mathrm{Zn}_{0.5}$ ferrite powders and their characterizations. Mater Lett 2002, 57(2):291-296.

29. Kasapoglu N, Birsöz B, Baykal A, Köseoglu Y, Toprak M: Synthesis and magnetic properties of octahedral ferrite $\mathrm{Ni}_{x} \mathrm{CO}_{1-x} \mathrm{Fe}_{2} \mathrm{O}_{4}$ nanocrystals. Cent Eur J Chem 2007, 5(2):570-580.

30. Rashad MM, Elsayed EM, Moharam MM, Abou-Shahba RM, Saba AE: Structure and magnetic properties of NixZn1 - xFe2O4 nanoparticles prepared through co-precipitation method. J Alloys Compd 2009, 486(12):759-767.

31. Kavas H, Kasapoglu N, Baykal A, Kaseoglu Y: Characterization of NiFe2O4 nanoparticles synthesized by various methods. Chem Papers 2009, 63(4):450-455.

32. Nathani $H$, Gubbala S, Misra RDK: Magnetic behavior of nanocrystalline nickel ferrite: Part I. The effect of surface roughness. Mater Sci Eng B 2005, 121(1-2):126-136.

33. Kodama RH, Berkowitz AE, McNiff JEJ, Foner S: Surface Spin Disorder in $\mathrm{NiFe}_{2} \mathrm{O}_{4}$ Nanoparticles. Phys Rev Lett 1996, 77(2):394-397.

34. Manova E, Tsoncheva T, Estournes C, Paneva D, Tenchev K, Mitov I, Petrov L: Nanosized iron and iron-cobalt spinel oxides as catalysts for methanol decomposition. Appl Catal A 2006, 300(2):170-180.

35. Li G-y, Jiang Y-r, Huang K-I, Ding P, Chen J: Preparation and properties of magnetic $\mathrm{Fe}_{3} \mathrm{O}_{4}$-chitosan nanoparticles. J Alloys Compd 2008, 466(12):451-456.

36. Zhi J, Wang Y, Lu Y, Ma J, Luo G: In situ preparation of magnetic chitosan/Fe3O4 composite nanoparticles in tiny pools of water-in-oil microemulsion. Reac Funct Polym 2006, 66(12):1552-1558.

37. Smit J, Wijn HPJ: Ferrite. London: Cleaver-Hume Press; 1959.
38. Nathani H, Misra RDK: Surface effects on the magnetic behavior of nanocrystalline nickel ferrites and nickel ferrite-polymer nanocomposites. Mater Sci Eng B 2004, 113(3):228-235.

39. Nawale AB, Kanhe NS, Patil KR, Bhoraskar SV, Mathe VL, Das AK: Magnetic properties of thermal plasma synthesized nanocrystalline nickel ferrite $\left(\mathrm{NiFe}_{2} \mathrm{O}_{4}\right)$. J Alloys Compd 2011, 509(12):4404-4413.

40. Pradeep A, Priyadharsini P, Chandrasekaran G. Production of single phase nano size NiFe2O4 particles using sol-gel auto combustion route by optimizing the preparation conditions. Mater Chem Phys 2008, 112(2):572-576.

41. Gabal MA, Al Angari YM, Kadi MW: Structural and magnetic properties of nanocrystalline $\mathrm{Ni}_{1-x} \mathrm{Cu}_{x} \mathrm{Fe}_{2} \mathrm{O}_{4}$ prepared through oxalates precursors. Polyhedron 2011, 30(6):1185-1190.

doi:10.1186/1752-153X-6-23

Cite this article as: Nejati and Zabihi: Preparation and magnetic properties of nano size nickel ferrite particles using hydrothermal method. Chemistry Central Journal 2012 6:23.

Publish with ChemistryCentral and every
scientist can read your work free of charge
"Open access provides opportunities to our
colleagues in other parts of the globe, by allowing
anyone to view the content free of charge."
W. Jeffery Hurst, The Hershey Company.
- available free of charge to the entire scientific community
- peer reviewed and published immediately upon acceptance
- yours - you keep the copyright
Submit your manuscript here:
http://www.chemistrycentral.com/manuscript/

